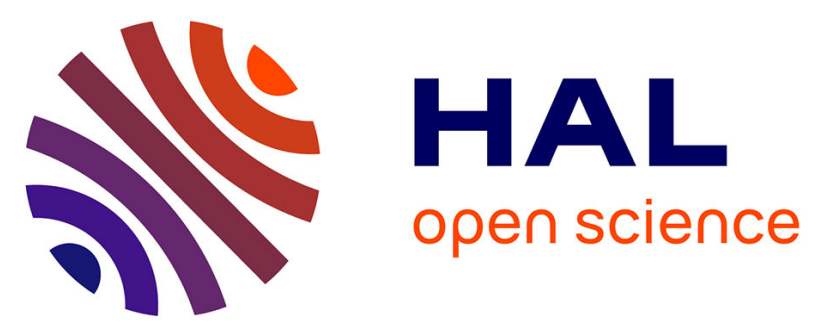

\title{
In situ experiments to assess effects of constraints linked to caging on ecotoxicity biomarkers of the three-spined stickleback (Gasterosteus aculeatus L.)
}

\author{
Antoine Le Guernic, Wilfried Sanchez, Olivier Palluel, Anne Bado-Nilles, \\ Cyril Turies, Edith Chadili, Isabelle Cavalie, Christelle Adam-Guillermin, \\ Jean-Marc Porcher, Alain Geffard, et al.
}

\section{To cite this version:}

Antoine Le Guernic, Wilfried Sanchez, Olivier Palluel, Anne Bado-Nilles, Cyril Turies, et al.. In situ experiments to assess effects of constraints linked to caging on ecotoxicity biomarkers of the three-spined stickleback (Gasterosteus aculeatus L.). Fish Physiology and Biochemistry, 2016, 42, pp.643-657. 10.1007/s10695-015-0166-2 . ineris-01862938

\section{HAL Id: ineris-01862938}

https://hal-ineris.archives-ouvertes.fr/ineris-01862938

Submitted on 28 Aug 2018

HAL is a multi-disciplinary open access archive for the deposit and dissemination of scientific research documents, whether they are published or not. The documents may come from teaching and research institutions in France or abroad, or from public or private research centers.
L'archive ouverte pluridisciplinaire HAL, est destinée au dépôt et à la diffusion de documents scientifiques de niveau recherche, publiés ou non, émanant des établissements d'enseignement et de recherche français ou étrangers, des laboratoires publics ou privés. 


\title{
In situ experiments to assess effects of constraints linked to caging on ecotoxicity biomarkers of the three-
} spined stickleback (Gasterosteus aculeatus, L.).

\author{
Authors \\ Antoine Le Guernic ${ }^{1,2,3^{*}}$,Wilfried Sanchez ${ }^{2}$, Olivier Palluel ${ }^{2}$, Anne Bado-Nilles ${ }^{2}$, Cyril Turies ${ }^{2}$, Edith Chadili², \\ Isabelle Cavalié ${ }^{1}$, Christelle Adam-Guillermin ${ }^{1}$, Jean-Marc Porcher ${ }^{2}$, Alain Geffard ${ }^{3}$, Stéphane Betoulle ${ }^{3}$, \\ Béatrice Gagnaire ${ }^{1}$. \\ ${ }^{1}$ Institut de Radioprotection et de Sûreté Nucléaire (IRSN), PRP-ENV/SERIS/LECO, Centre de Cadarache, \\ 13115 Saint-Paul-lez-Durance, France. \\ ${ }^{2}$ Institut National de l'Environnement Industriel et des Risques (INERIS), UMR-I 02 SEBIO (Stress \\ Environnementaux et Biosurveillance des milieux aquatiques), BP 2, 60550 Verneuil-en-Halatte, France. \\ ${ }^{3}$ Université de Reims Champagne-Ardenne (URCA), UMR-I 02 SEBIO, UFR Sciences Exactes et Naturelles, \\ Campus Moulin de la Housse, B.P. 1039, 51687 Reims, France.
}

*Corresponding author: antoineleguernic@gmail.com, phone: +33442199632.

\begin{abstract}
The aim of this study was to evaluate the effects of caging constraints on multiple fish biomarkers used during ecotoxicological studies (biometric data, immune and antioxidant systems, and energetic status). Two of these constraints were linked to caging: starvation and fish density in cages, and one in relation to the post-caging handling: a short transport. Three in situ experiments were conducted with three-spined sticklebacks (Gasterosteus aculeatus). The first experiment compared the effects of three densities (low, medium, and high). The second experiment compared effects of starvation in fish fed every two days with fish that were not fed. Finally comparisons between sticklebacks which have suffered a short car transport after caging and sticklebacks sacrificed without preliminary transport were made. The lack of food had no effect on fish energetic reserves but negatively affected their condition index and their immune system. Transport and high density induced oxidative stress, defined as an overproduction of reactive oxygen species and a stimulation of the antioxidant system. These two constraints also harmed the leucocyte viability. In order not to have any impact on ecotoxicity biomarkers during in situ experiments, it is preferable to decrease fish density in cages, prevent transport before dissections and feed fish when the caging lasts more than two weeks.
\end{abstract}

\section{Headings}

- The effects of 20 minutes of car transport, three fish densities during caging and 14 days of starvation were evaluated on ecotoxicity markers in the three-spined stickleback.

- Transport induced an oxidative stress, while the highest density and starvation constraints modified the immune capacities of sticklebacks. 


\section{Keywords}

Density; Immunomarkers; Starvation; Transport.

\section{Introduction}

Awareness of diverse and numerous anthropogenic environmental contaminants have prompted an evaluation and monitoring of ecosystem quality, including aquatic habitats. These assessments require the chemical determination of pollutants, but also the determination of their effects on aquatic flora and fauna. Tools have been developed to observe and measure biochemical, physiological, histological, morphological and behavioural changes after exposure to pollutants (Lagadic et al. 1997a). These measurable changes are commonly called biomarkers. The analysis of a single biomarker is not sufficient to appreciate the overall pollution or its effects on the health of organisms. In addition, some biomarkers only react with a specific contamination, and studies focusing only on one or two biomarkers can miss some effects. Evaluation of pollution effects on several biological functions and responses facilitates the observation and understanding of damage caused by this pollution and thus a multi-biomarker approach is increasingly used in environmental studies (Lagadic et al. 1997b; Hinck et al. 2008; Sanchez et al. 2008a; Gagnaire et al. 2015).

In the context of environmental risk assessment (ERA), in situ experiments can involve complex interactions often impossible to reproduce in the laboratory (Pereira et al. 2006). One possible solution is to sample and analyse organisms already present on the polluted site. However, most environmental studies involve sentinel species and these species can be absent on the studied sites. Moreover, even if the sentinel species is present, the number of individuals required and the stress of capture can be limiting factors (Frisch and Anderson 2000; Campbell et al. 2009). To avoid these problems, caging can allow work under semi-controlled conditions in aquatic habitats while keeping the natural environmental complexity. Caging presents many advantages (Oikari 2006) including the selection of well characterised homogenous organisms (number, age, size, weight, sex), and the control of exposure (location, time, season). Caging allows, under certain limitations, the use of sentinel species not naturally present in the studied environment. Caging also limits predation stress and greatly facilitates sampling. Therefore caging is increasingly used in ecotoxicological studies, particularly with a multiple contamination (Cazenave et al. 2014; Scarcia et al. 2014; Gagnaire et al. 2015).

However, caging also presents disadvantages that may impact analysed responses during in situ experiments (Oikari 2006). The stress due to caging has been assessed many times via responses such as catecholamines, glucocorticoids, and the levels of glucose or lactate (Pickering et al. 1991; Brydges et al. 2009), but few studies have focused on the possible modulations of biomarkers commonly used in ecotoxicological studies following caging. Biases caused from caging can hide the results by decreasing the statistical power of the experiment, and can be more apparent than the effects of the pollutants. Trevisan et al. (2013) have observed that the confinement of Nile tilapia, Oreochromis niloticus, induced stress which resulted in higher effects on some biomarkers than those induced by a polymetallic contamination. Our study presents an original approach by assessing effects due to 14 days of caging on biomarkers popularly used during ecotoxicological studies. Consequently, effects of two constraints linked to caging (starvation, fish density) and another due to handling post-caging (20 min of transport) were investigated using a multi-biomarker approach. The biomarkers analysed were related to physiology, defense capabilities, such as the antioxidant and immune systems, and also to energetic reserves. In 
situ experiments were conducted with three-spined stickleback (Gasterosteus aculeatus), a fish species with useful features for in situ experiments. Sticklebacks are robust fish (Pottinger et al. 2002) and because of their small size, handling and caging are facilitated. The use of sticklebacks as a sentinel species for ecotoxicological studies has been noted repeatedly (Pottinger et al. 2002; Sanchez et al. 2007; Knag and Taugbøl 2013).

\section{Material and methods}

\subsection{Caging characteristics}

The cylindrical cages used in this study were $460 \mathrm{~mm}$ heigh with a radius of $125 \mathrm{~mm}$ (volume $=22.58 \mathrm{~L}$ ). In order to sacrifice fewer sticklebacks while maintaining the desired density, cages could be divided in two by adding a wall. The cage mesh was $3.5 \mathrm{~mm}$ x $3.5 \mathrm{~mm}$, which allowed water and particle flows and prevented fish from escaping. Cages were placed directly on the sediment at a water depth of $50 \mathrm{~cm}$. Before being caged, fish were acclimated in the laboratory to physical and chemical conditions of each study site for two weeks (temperature, $\mathrm{pH}$, conductivity). For each experiment, one year old three-spined sticklebacks from INERIS animal husbandry were used from the same initial fish group to limit individual variations. Fish were transported by car from INERIS to each caging site in several closed buckets containing water from their acclimation phase and previously super-oxygenated.

Conductivity and $\mathrm{pH}$ of water for each experiment were assessed a first time when the caging started, and a second time when the experiment was over. Temperature was recorded each hour using a probe hooked to the cage (HOBO Pendant Temperature Data Logger, Onset, Bourne, MA, USA).

\subsection{Caging experiments}

Constraints tested in this study were: $i)$ fish density in cages $\left(2.31 \mathrm{~kg} / \mathrm{m}^{3}\right.$ and $\left.\left.3.54 \mathrm{~kg} / \mathrm{m}^{3}\right), i i\right)$ starvation and iii) 20 minutes of transport before dissections. Each caging condition was compared to one different reference condition. For fish density in cages, the reference condition was a density of $1.08 \mathrm{~kg} / \mathrm{m}^{3}$, and this density was chosen in accordance with OECD guidelines (OECD 2000). Potential effect of 14 days starvation was assessed by comparing fish starved with fish fed every two days. Then, transportation effects were compared to fish sacrificed without transport. The transport and density experiments were conducted in a pond in the HauteVienne department (France), in April 2014 and October 2014 respectively, while the starvation experiment was carried out in November 2013 in a stream located in the Oise department (France). Characteristics of each experiment and water physical and chemical parameters are reported in the figure 1.

Forty-five sticklebacks $(1.76 \pm 0.28 \mathrm{~g} ; 5.83 \pm 0.29 \mathrm{~cm}$; female/male sex ratio of 1.25$)$ were used for the density experiment and were distributed in three cages divided in two parts: seven sticklebacks in a cage (density of 1.08 $\mathrm{kg} / \mathrm{m}^{3}$ ), 15 sticklebacks in another cage (density of $2.31 \mathrm{~kg} / \mathrm{m}^{3}$ ) and 23 sticklebacks (density of $3.54 \mathrm{~kg} / \mathrm{m}^{3}$ ) in a third. During this experiment, sticklebacks were not fed. Fourteen days after caging, sticklebacks were sacrificed by cervical dislocation directly on the field, without transport before dissection. 
Sixty sticklebacks $(1.88 \pm 0.41 \mathrm{~g} ; 5.84 \pm 0.44 \mathrm{~cm}$; female/male sex ratio of 1.31$)$ distributed in two cages (30 fish per cage without walls; density: $2.31 \mathrm{~kg} / \mathrm{m}^{3}$ ) were used to highlight the possible effect of starvation on ecotoxicity biomarkers. Fish from one cage were fed every two days with bloodworms (ratio of food/fish of $6 \%$ w/w every two days, Ocean Nutrition Europe, Essen, Belgium), while sticklebacks from the other cage were not fed. Fourteen days after caging, sticklebacks were sacrificed by cervical dislocation directly on the field, without transport before dissection.

In order to determine the effect of a short transport on stickleback responses, thirty sticklebacks $(1.35 \pm 0.16 \mathrm{~g}$; $5.41 \pm 0.20 \mathrm{~cm}$; female/male sex ratio of 1.14) distributed in two cages divided in two parts (15 fish per cage; $2.31 \mathrm{~kg} / \mathrm{m}^{3}$ ) were used. During this experiment, sticklebacks were not fed. Fourteen days after caging, 15 sticklebacks were removed from their cage and immediately sacrificed by cervical dislocation, while the other 15 fish from the other cage were directly placed into closed buckets, transported by car for 20 minutes and then were sacrificed. During this short transport, the buckets contained the water of the pond in which fish were caged, and the same stickleback distribution and density were kept.

For each experiment, stickleback size, total and liver weights were recorded to calculate physiological indices, and the spleen was recovered for the immune system analyses. The splenic leucocyte isolation was performed following previous described method (Bado-Nilles et al. 2014b). In the field, spleens were pressed through sterilized nylon mesh (40 $\mu \mathrm{m}$, Becton Dickinson, NJ, USA) with Leibovitz 15 medium (L15, Sigma, St. Louis, MO, USA) modified with heparin lithium (10 U/mL, Sigma), penicillin (500 U/mL, Sigma), and streptomycin (500 $\mu \mathrm{g} / \mathrm{mL}$, Sigma). The leucocyte suspension obtained was stored at $4{ }^{\circ} \mathrm{C}$ for 18 hours prior to analysis. During the density and transport experiments, the liver was recovered for the antioxidant system analyses, while during the starvation experiment the entire liver was used to assess energetic reserves (total lipids, glycogen, free sugars). In the field, livers were extracted, weighed, and placed in $400 \mu \mathrm{L}$ of potassium phosphate buffer (100 mM, pH 7.4) modified with glycerol (20\%, Sigma) and phenylmethylsulfonyl fluoride (PMSF, $2 \mu \mathrm{M}$, Sigma) in order to inhibit proteolysis. These livers were then frozen in liquid nitrogen and stored in freezer at $-80{ }^{\circ} \mathrm{C}$ until oxidative stress analyses. Otherwise, livers used for energetic reserves were immediately removed from fish, weighed and frozen without buffer. They also were kept at $-80^{\circ} \mathrm{C}$ until analyses.

\subsection{Biological parameters}

\subsubsection{Biometric data}

Fulton's K condition index $(\mathrm{K})$ evaluates the general well-being of fish and is calculated by the formula: $\mathrm{K}=$ $\left(\right.$ weight/length $\left.{ }^{3}\right) \times 100$. The hepato-somatic index $($ HSI $)$ is calculated by the formula: HSI = (liver weight/total body weight) $\times 100$.

\subsubsection{Immune capacities}

Leucocyte necrosis, apoptosis, percentage of lymphocyte among leucocytes, lysosomal membrane integrity (LMI), respiratory burst, and phagocytic capacity were analysed following protocols previously described 
(Bado-Nilles et al. 2013; Bado-Nilles et al. 2014a; Gagnaire et al. 2015). Respiratory burst is described by three parameters: ROS basal level, corresponding to ROS production by unstimulated cells; ROS activated, corresponding to ROS production in cells stimulated by phorbol 12-myristate 13-acetate (PMA, Sigma) and the stimulation index of respiratory burst, which is calculated by the formula: fluorescence of ROS activated / fluorescence of ROS basal (Chilmonczyk and Monge 1999). Leucocyte activities were evaluated by flow cytometry with 10,000 events counted for each suspension sample. Data of density and transport experiment were recovered using a Guava®EasyCyteTM 8HT flow cytometer (Merck Millipore, Billerica, MA, USA) and analysed using Guavasoft 2.7 software, while analyses of starvation experiment were carried out using a Cyan ADP flow cytometer (Beckman Coulter, Fullerton, CA, USA) with Summit 4.3 software.

\subsubsection{Oxidative stress}

Protein concentration was assessed using Bradford (1976) method with bovine serum albumin (Sigma for the two products). Among hepatic biomarkers, glutathione (GSH) (Vandeputte et al. 1994), glutathione-S-transferase (GST) (Habig et al. 1974), glutathione peroxidase (GPx) (Paglia and Valentine 1967), glutathione reductase (Gr) (Carlberg and Mannervik 1975), catalase (CAT) (Babo and Vasseur 1992), superoxide dismutase (SOD) (Paoletti et al. 1986), and thiobarbituric acid reactive substances (TBARS) for lipid peroxidation assessment (Ohkawa et al. 1979), were analysed. All these measurements were adapted for stickleback by Sanchez et al. (2005) and Sanchez et al. (2007). Except for TBARS and GSH (mol/g of total protein), all results were calculated in $\mathrm{U} / \mathrm{g}$ of total protein.

\subsubsection{Energetic reserves}

Energetic reserves were assessed only in the starvation experiment. The entire stickleback liver was required for these analyses; therefore the assessment of the oxidative status of the unfed sticklebacks could not be performed. Lipid and glycogen assays were performed according to Frings et al. (1972) and Carr and Neff (1984) protocols, respectively. According to the calibration curve (glucose, from 0 to $0.6 \mathrm{mg} / \mathrm{mL}$ in ultrapure water, Sigma for glycogen and free sugar assays; triolein, from 0 to $5 \mathrm{mg} / \mathrm{mL}$ in the chloroform / methanol mix, Sigma for lipid assay), and to the volume of glycogen and free sugar homogenates, glycogen and free sugar reserves were expressed in percentage relative to the liver weight. Lipid measurements were adapted to fish and to microplate by Péry et al. (2014).

\subsection{Statistical analyses}

Results of the density, starvation and transport experiments were expressed as the ratio to fish without stress (caged with the lowest density, fish that were fed every two days, and fish that were not transported before being sacrificed, respectively). These ratios were made by dividing individual values of stressed fish over the mean results obtained without stress. Statistics were produced from all the values (including variability of control groups), not from the ratios. Numeric results are inscribed in the table in Table 1. 
$\mathrm{R}$ software (3.1.1 version) was used for all statistical analyses. The number of replicates depends on the experiment $(\mathrm{N}=7,14$ or 22 for density experiment; $\mathrm{N}=30$ for food experiment; $\mathrm{N}=15$ for transport experiment).

Concerning the density experiment, a one-way analysis of variance (ANOVA) was performed. Normality and homogeneity of variances of ANOVA residuals were assessed by the Shapiro-Wilk and Levene tests, respectively ( $\alpha=5 \%$ ). If normality and homoscedasticity were respected, ANOVA was kept and was followed by a Tukey test, otherwise, ANOVA was replaced by a Kruskal-Wallis test followed by a Mann-Whitney test ( $\alpha$ $=5 \%$ ).

Concerning the transport and starvation experiments, normality and homogeneity of variances were tested using the Shapiro-Wilk and Fisher tests, respectively $(\alpha=5 \%)$. If normality and homoscedasticity were respected, the Student test was performed, otherwise, Student test was replaced by the Wilcoxon test $(\alpha=5 \%)$. Males and females were grouped as there was no sex effect on biomarkers analysed.

\section{Results}

\subsection{Water Physical and chemical parameters}

The minimum and maximum $\mathrm{pH}$ and conductivity, as well as the mean temperature for each experiment are included in figure 1 . These parameters varied according to period and exposure.

\subsection{Individual mortality}

Two sticklebacks died during the density experiment (one in the medium density and one in the highest density cage). No deaths occurred during the other two experiments. Moreover, no external sign of stress (skin coloration, injuries), as well as no behavioural alteration were observed after caging (abnormal reaction when out of water, no swimming).

\subsection{Fish density in cage}

High individual variations were seen among conditions, and no significant difference for all biometric data was observed between sticklebacks caged with the lowest, the medium or the highest densities (Table 1; Figure 2). The highest density caused higher LMI in fish spleen compared to sticklebacks caged with the lowest density ( $p$ $\left.=3.04 \times 10^{-2}\right)($ Table 1 ; Figure 3). ROS basal level tended to increase with density but not significantly, while ROS activated level was significantly enhanced by the highest density compared to the medium and the lowest densities ( $p=4.55 \times 10^{-2}$ compared with the medium density and $p=1.38 \times 10^{-2}$ with the lowest density) (Table 1; Figure 3). No effect of a low or a high density was observed on phagocytic capacity, on lymphocyte percentage, on antioxidant system or on lipid peroxidation ( $\mathrm{Gr}$ activity could not be assessed for density conditions) (Table 1; Figure 4). It should be noted a non-significant increase in apoptosis between the lowest and highest density $\left(p=9.45 \times 10^{-2}\right)$. This increase became significant between the intermediate density and the highest $\left(p=4.75 \times 10^{-2}\right)($ Table 1; Figure 3$)$. 


\subsection{Starvation}

Starvation was the only constraint which caused a decrease of $\mathrm{K}\left(p=4.25 \times 10^{-2}\right)$ (Table 1 ; Figure 2). Concerning immune system, fish which were starved had higher leucocyte necrosis and apoptosis than fish fed every two days $\left(p=4.06 \times 10^{-2}\right.$ and $p=1.14 \times 10^{-3}$, respectively) (Table 1 ; Figure 3$)$. Correlatively, LMI was reduced when sticklebacks received no supplementary food $\left(p=7.13 \times 10^{-3}\right)$, while ROS basal level strongly increased during fasting $\left(p=6.42 \times 10^{-4}\right)$. This rise was reflected in a decrease in the stimulation index of respiratory burst $\left(p=2.23 \times 10^{-3}\right)$ (Table 1 ; Figure 3$)$. Phagocytic capacity also was reduced in fish unfed ( $p=$ $\left.6.65 \times 10^{-3}\right)$. No significant difference was observed on energetic reserves between sticklebacks fed or sticklebacks without supplementary food (Table 1).

\subsection{Short transport before dissection}

Transport had no effect on biometric data (Table 1; Figure 2). However, transport decreased significantly leucocyte apoptosis $\left(p=6.30 \times 10^{-3}\right)$, and strongly increased the ROS basal level $\left(p=6.24 \times 10^{-5}\right)($ Table 1 ; Figure 3). The result on stimulation index was a significant decrease caused by transport $\left(p=3.01 \times 10^{-5}\right)$. Despite high individual variations, 20 minutes of transport induced increases of all antioxidant biomarkers and lipid peroxidation, and four of these increases were significant $\left(p=6.16 \times 10^{-3}\right.$ for GSH; $p=1.18 \times 10^{-2}$ for GST; $p=3.62 \times 10^{-2}$ for SOD; $p=4.56 \times 10^{-2}$ for TBARS) (Table 1; Figure 4).

\section{Discussion}

\subsection{Experimental design}

Fourteen days between transport from INERIS to study sites and dissection were respected in order to no assess the potential manipulation and transport stress. Indeed, studies have demonstrated that two weeks of latency after handling and transport were sufficient to overcome this stress (Pickering et al. 1982; Möck and Peters 1990; Acerete et al. 2004). In addition, 14 days is a common sampling time during ecotoxicological studies with caging (Haasch et al. 1993; Fenet et al. 1998; Gagnaire et al. 2015).

The three in situ experiments were conducted in different periods and localisations, thus resulting in different water parameters (temperature, $\mathrm{pH}$, conductivity, Figure 1). These differences did not allow comparisons of results between experiments, and explained the differences of basal levels of biomarkers recorded between experiments (Table 1). Seasonal variability of fish biomarkers has already been reported in several studies (De Andrade et al. 2004; Sanchez et al. 2008b; Oliva et al. 2012; Bado-Nilles et al. 2015).

Nonetheless, within each experiment, sticklebacks were subject to the same environmental conditions. Moreover, fish were acclimated in the laboratory to these environmental parameters according to study site and caging period. The only difference applied to fish within an experiment was the caging characteristic tested (fish density, transport before dissection and starvation). Among each experiment, sticklebacks were originated from the same animal husbandry and were the same age, decreasing individual variations. 
For all these reasons, comparison of results between the different caging conditions for a given experiment can be performed.

\subsection{Effects of density on fish biomarkers}

For in situ experiment requiring caging, it is preferable to decrease stress by transporting fish in containers that are similar to those in which they will be experimentally caged (Oikari 2006), and also to decrease fish density in cages and use multiply cages for statistics. But sometimes, field experiments induces limits, like the number of fish or transportable cages that can be used. Moreover, the European Directive 2010/63 EU requires, among other things, a reduction in the number of animals used for scientific purposes. Densities used until now can be modified to be consistent with this directive and the results previously obtained may be varied.

Many studies evidenced induction of stress biomarkers (cortisol and lactate) with confinement and high density (Pickering et al. 1991; Vazzana et al. 2002; Urbinati et al. 2004). Our results showed that the more fish density increased, the more the biomarkers were modified. After 14 days of caging, condition index tended to decrease for fish caged with the highest density compared to fish caged with the lowest density. Nevertheless, this difference was not significant. Some studies reported decreases of condition index due to high density confinement, but with a longer period of this stress. Pickering et al. (1991) highlighted a decrease of the condition index, when rainbow trout, Oncorhynchus mykiss, were submitted to at least five months of chronic crowding. Andrade et al. (2015) highlighted the same effect on the Senegalese sole, Solea senegalensis, after 60 days at high density. It could be that if the caging time of our study was more important, the condition index of fish caged with the highest density would significantly decrease. Kiron (2012) reported that fish density, as transport, is stressful for fish and can be immunosuppressive. In our study, the increase of stickleback density in cages had negative effects on their immune capacities. Leucocyte necrosis and apoptosis tended to be higher, but not significantly, in fish caged with the highest density compared to the other two densities (leucocyte apoptosis was nonetheless significantly higher in sticklebacks caged with the highest density compared to the medium density). LMI was greater with the highest fish density. The LMI decrease is linked to leucocyte necrosis and apoptosis, as well as to an increase of ROS production (Hultin 1995; Pompéia et al. 2000; Bado-Nilles et al. 2013). However, in our study, leucocyte apoptosis and ROS basal level increased with density. This increase of LMI level was not logical according to the other immune responses. It is possible that the increase of the fluorescence was not due to greater lysosomal membrane integrity, but rather due to a higher number of lysosomes. This hypothesis is supported by the fact that the differences in red fluorescence used for LMI between conditions were not observed with the green fluorescence (data not shown), and by a higher ROS production in fish caged with the highest density, often accompanied by enzymes released by the lysosome. Ruane et al. (1999) observed a decrease of leucocyte number in rainbow trout and brown trout, Salmo trutta, with a confinement stress. In our study, no difference of lymphocyte percentage was seen. The increase of fish density in cages also increased respiratory burst. ROS production (ROS activated levels) was higher with the highest density compared to the other two densities. ROS production can be influenced by many variables including crowding (Andrade et al. 2015). This can be due to energetic demands imposed by crowding (Trenzado et al. 2009). Other studies showed that immune capacities can be affected after confinement stress. Twenty-three hours after confinement stress, oxygen radical production of brown trout increased (Ruane et al. 
1999). A high fish density can suppress immune capacities (respiratory burst and phagocytosis) (Vazzana et al. 2002). The increase in ROS production can create an oxidative stress, and therefore can induce the establishment of the antioxidant system. Nevertheless, in our study, fish density did not impact antioxidant system or induce lipid peroxidation, unlike in other studies. Trevisan et al. (2013) showed that high fish density altered parts of the antioxidant system (GSH and GST) of Nile tilapia, and these effects were higher than effects of a polymetallic contamination. Correlatively, Andrade et al. (2015) reported lower SOD, GPx, Gr activities and higher lipid peroxidation when Senegalese sole were kept 60 days at high density compared to low density. Although 14 days of caging is a short duration, Trevisan et al. (2013) observed these effects after 7 days of caging. Our differences in results with other studies may be due to the species. Indeed, responses to confinement and density stress depended to the species caged (Ruane et al. 1999; Caruso et al. 2005), and the developmental stage studied. Some of these studies focused on juvenile fish (Ruane et al. 1999; Andrade et al. 2015), while our study was used adults. Moreover, it is important to differentiate fish density in tanks at the laboratory or aquaculture (Ruane et al. 1999; Vazzana et al. 2002; Andrade et al. 2015) and caging in the field (Trevisan et al. 2013). Indeed, water volume inside tanks is limited and not constantly renewed compared to in situ caging.

In our study, the highest density induced stress on sticklebacks, particularly on immunity. No significant difference was observed between biomarkers from sticklebacks caged with the lowest density and those from sticklebacks caged with the intermediate density. For further in situ experiments on adult sticklebacks, we recommend the use of a low fish density in cages $\left(1.08\right.$ or $\left.2.31 \mathrm{~kg} / \mathrm{m}^{3}\right)$ in order to limit modulations of ecotoxicity immunomarkers caused by a high density $\left(3.54 \mathrm{~kg} / \mathrm{m}^{3}\right)$. It is also preferable to cage social fish, or gregarious fish, and avoid breeding period, to eliminate competition and cannibalism between fish (Oikari 2006).

\subsection{Effects of starvation on fish biomarkers}

During an in situ experiment, the study site can be far from the laboratory and providing food daily to the caged fish can be difficult. That is one reason why it is important to estimate the effect of starvation on fish during caging procedure. The diet of the three-spined stickleback is made up of small invertebrates, such as worms, insects or crustaceans, as well as larvae or plankton (Hynes 1950; Allen and Wootton 1984). The meshes of our cage $(3.5 \times 3.5 \mathrm{~mm})$ allowed the passage of these organisms. For fish caged in one cage, the food supply / fish ratio (6\% every two days) was estimated according to several studies (Allen and Wootton 1982; Triglidae 1998; Richter et al. 2002; Pascual et al. 2003; Craig and Helfrich 2009; Bado-Nilles et al. 2014b). Sticklebacks without supplementary food were not subject to a nutritional stress, proven by energetic reserves. Indeed, no significant differences of free sugars, lipid and glycogen contents were observed between livers from fish which received no supplementary food compared to livers from fed fish. These results can be explained by our short period of fasting. Indeed, most studies working on the effects of fasting lasted from two to nine weeks and fish from these studies did not have access to other potential food sources, unlike our sticklebacks, which can eat what passed through the mesh (Blom et al. 2000; Regost et al. 2001; Caruso et al. 2011; Gimbo et al. 2015). One month of starvation resulted in a decrease in lipid levels in the pacu, Piaractus mesopotamicus, but it was not enough to cause a decrease in glycogen content in the liver of this fish (Gimbo et al. 2015). Despite a lack of significant differences in energetic reserves, our unfed sticklebacks had a lower $\mathrm{K}$ than fish fed every two days. A two week starvation was enough to induce a decrease of the three-spined stickleback condition index (Pottinger et al. 2002). This decrease was observed in other studies, but with longer periods of starvation. For rainbow trout, a 
decrease of condition index was observed after two weeks of starvation and a weight loss after 6 or 7 weeks (Sumpter et al. 1991; Blom et al. 2000). Regost et al. (2001) observed that a fat diet increased condition index of brown trout and a starvation resulted in a decrease of this index after 12 weeks of starvation. In our study, no difference concerning HSI was observed. Blom et al. (2000) found a decrease of rainbow trout HSI after 3 and 7 weeks of starvation. Similarly, HSI of brown trout decreased after 2 months of starvation (Regost et al. 2001). Therefore, we hypothesize that two weeks of starvation is not enough to induce an effect on this index in threespined sticklebacks.

Among treatments tested in this study, the lack of food induced the most effects on fish immune system. Except the lymphocyte percentage, starvation induced increases of leucocyte necrosis, apoptosis, and ROS basal level, while LMI and phagocytic capacity were reduced with starvation. Lipids are important for leucocyte and lysosomal membrane integrities. Lipids are constituents of membranes and are involved in the synthesis of several immune protagonists (Lall 2000; Kiron 2012; Henry and Fountoulaki 2014). A change in lipid amounts or nature can be detrimental for fish immunity (Lall 2000). The slight and not significant decrease of lipids contents can affect cell membranes, and thus negatively affect leucocyte integrity (leucocyte necrosis, apoptosis and LMI) shown in our study.

Immune cells need nutrients to activate their functions, including phagocytosis. Although fasting had no effect on hepatic reserves, deficiencies of certain nutrients might explain the reduction of phagocytic capacity in unfed sticklebacks. Lall (2000) highlighted the importance of lipids in phagocytic process. Some fatty acids are essentials to keep membrane fluidity and therefore are essentials to the ingestion phase of phagocytosis (Lall 2000). Starvation was the only constraint tested in our study that had repercussions to the phagocytic capacity. Therefore, this decrease of phagocytic capacity also can be due to the slight reduction in lipid contents. Another hypothesis to explain this decrease of phagocytic capacity is that carbohydrates (glycogen and glucose), in addition to their utility in energy production, are involved directly or indirectly in the regulation of immune function (Secombes and Fletcher 1992; Waagb Ø 1994). The slight and not significant decrease of glycogen content may explain a decrease of phagocytic capacity. Several studies have pointed out that a lack or an excess of carbohydrate (included glycogen and glucose) levels affect the fish physiology and immune system and their resistance during a challenge against pathogens (WaagbØ 1994; Li et al. 2012). These immunosuppressive effects of the lack of carbohydrate may be the cause of the decrease in phagocytic capacity observed in our study in fish with no supplementary food.

Although stickleback phagocytic capacity was reduced by starvation, ROS basal level was enhanced by this constraint. Martínez-Álvarez et al. (2005) also reported oxidative stress after starvation. Immune capacities are energetically costly (Gimbo et al. 2015). However, two important energy sources are glycogen and glucose, and the glycogen in fish liver can be used to release glucose after fasting (Hemre et al. 2002). Glycogen cost for respiratory burst may explain the slight decrease of glycogen contents in our study. In other studies, immune capacities were reduced with starvation, for example in the European seabass, Dicentrarchus labrax, or in the pacu, which presented a lower respiratory burst after 30 or 31 days of starvation (Caruso et al. 2011; Gimbo et al. 2015).

Our study showed that stickleback starvation during caging can be conducted for two weeks without having repercussions on energetic reserves. Nonetheless, some immunomarkers can react with starvation, thus it is better to feed fish continuously over caging. The choice of species and diet is crucial before performing an in situ 
experiment involving caging. Similarly, if starvation is performed, it is necessary to choose a fish species with a large diet (Oikari 2006).

\subsection{Effects of a short transport on fish biomarkers}

In order to facilitate dissections, it is sometimes necessary to transport fish at the dissection place or in the laboratory. This transport is often short, but can create a stress. Few studies assessed stress of a short transport (less than one hour). In a general manner, studies which assessed transport effects showed a stress on fish, by quick increases of cortisol and blood glucose concentrations (Möck and Peters 1990; Frisch and Anderson 2000; Acerete et al. 2004; Urbinati et al. 2004; Tacchi et al. 2015). In our study, transport impacted the immune system by increasing ROS basal level. Interestingly, 20 minutes of transport decreased leucocyte necrosis and apoptosis. Transport can affect skin and mucus, the first barriers against pathogens (Tacchi et al. 2015). Twenty minutes of transport induced a global increase of antioxidant system and lipid peroxidation. This increase was correlated with the increase of ROS production. Antioxidant responses can be transient and be indicative of a stress (Sanchez et al. 2005; Valavanidis et al. 2006). Transport effect can be reversible and be attenuated rapidly when stopped (Möck and Peters 1990; Frisch and Anderson 2000; Urbinati et al. 2004). The significant effects on some biomarkers faded between 4 to 72 hours after the end of the transport (Frisch and Anderson 2000; Urbinati et al. 2004).

Transport stress was defined on sticklebacks by an oxidative stress (increase of ROS production and stimulation of the antioxidant system). However, this stress may be transient because of the short duration of transport. It would have been interesting to assess these biomarkers one hour after transport to confirm this hypothesis.

\section{Conclusion}

This study evaluated effects of two constraints linked to caging (fish density in cage and starvation) and one linked to handling post-caging (a short transport) on ecotoxicity biomarkers of the three-spined stickleback. Environmental studies using caged sticklebacks can be achieved with densities of 1.08 and $2.31 \mathrm{~kg} / \mathrm{m}^{3}$ without having repercussions on biomarkers. Indeed, no significant difference was observed between the medium and the lowest density. Only the highest density $\left(3.54 \mathrm{~kg} / \mathrm{m}^{3}\right)$ induced stress resulting in increases in ROS production. Fourteen days of starvation did not reduce energetic reserves contained in the stickleback livers. Nevertheless, some modulations of immune capacities were observed during this experiment. Further studies should be conducted to explain these immunomodulations after fasting for 14 days. A short transport between caging and dissection induced oxidative stress in sticklebacks, evident by increases in ROS production and antioxidant activities. Avoiding transport before dissection, caging system with the medium and the lowest densities and without food supply is valid with stickleback for two weeks in a context of ERA. Having the same caging conditions is the most important experimental design when using cages to study ERA. Improvements in this caging system are nonetheless possible, as increasing the contact cage-sediment to improve food availability or limiting transport before dissection.

\section{Acknowledgments}

The authors are deeply grateful to the owners of the different study sites for having allowed these environmental experiments. This work was partly supported by IRSN, the financial support of the 181 DRC 46 program of the 
French Ministry for Ecology and Sustainable Development, and the ECCOREV research federation. The authors are grateful to Tom Hinton for his help in correcting the English form of this paper.

\section{Compliance with ethical standards}

These experiments were conducted in accordance with the European Commission's recommendation 2007/526/EC on revised guidelines for the accommodation and care of animals used for experimental and other scientific purposes. The registration number for ethics of INERIS laboratory is B60-769-02. For sampling, to avoid bias in the immune responses, no anaesthetic overdose can be used for euthanasia of sticklebacks. Indeed, in the 2010/63 / EU Directive of the European Parliament and the 22 September 2010 Council about the protection of animals used for scientific purposes, this option is envisaged "if anesthesia is incompatible with the purpose of the procedure". Therefore, sticklebacks were rapidly sacrificed by cervical dislocation followed by destruction of the brain. This method has been approved by Committee No. 96-CREMEAP (Regional Ethics Committee in Animal Experimentation of Picardy).

\section{References}

Acerete L, Balasch JC, Espinosa E, Josa A, Tort L (2004) Physiological responses in Eurasian perch (Perca fluviatilis, L.) subjected to stress by transport and handling Aquaculture 237:167-178 doi:http://dx.doi.org/10.1016/j.aquaculture.2004.03.018

Allen J, Wootton R (1982) The effect of ration and temperature on the growth of the three-spined stickleback, Gasterosteus aculeatus L Journal of Fish Biology 20:409-422

Allen JRM, Wootton RJ (1984) Temporal patterns in diet and rate of food consumption of the threespined stickleback (Gasterosteus aculeatus L.) in Llyn Frongoch, an upland Welsh lake Freshwater Biology 14:335-346 doi:10.1111/j.1365-2427.1984.tb00158.x

Andrade $\mathrm{T}$ et al. (2015) Evaluation of different stocking densities in a Senegalese sole (Solea senegalensis) farm: Implications for growth, humoral immune parameters and oxidative status Aquaculture 438:6-11 doi:http://dx.doi.org/10.1016/j.aquaculture.2014.12.034

Babo S, Vasseur P (1992) In vitro effects of Thiram on liver antioxidant enzyme activities of rainbow trout (Oncorhynchus mykiss) Aquatic toxicology 22:61-68

Bado-Nilles A, Betoulle S, Geffard A, Porcher JM, Gagnaire B, Sanchez W (2013) Flow cytometry detection of lysosomal presence and lysosomal membrane integrity in the three-spined stickleback (Gasterosteus aculeatus L.) immune cells: applications in environmental aquatic immunotoxicology Environmental science and pollution research international 20:2692-2704 doi:10.1007/s11356-012-1410-2

Bado-Nilles A et al. (2014a) Applications in environmental risk assessment of leucocyte apoptosis, necrosis and respiratory burst analysis on the European bullhead, Cottus sp Environ Pollut 184:9-17 doi:10.1016/j.envpol.2013.07.049

Bado-Nilles A, Techer R, Porcher JM, Geffard A, Gagnaire B, Betoulle S, Sanchez W (2014b) Detection of immunotoxic effects of estrogenic and androgenic endocrine disrupting compounds using splenic immune cells of the female three-spined stickleback, Gasterosteus aculeatus (L.) Environmental toxicology and pharmacology 38:672-683 doi:http://dx.doi.org/10.1016/i.etap.2014.08.002

Bado-Nilles A et al. (2015) Recommendations to design environmental monitoring in the European bullhead, Cottus sp., based on reproductive cycle and immunomarker measurement Marine pollution bulletin 95:576-581

Blom S, Andersson TB, Förlin L (2000) Effects of food deprivation and handling stress on head kidney $17 \alpha$-hydroxyprogesterone 21-hydroxylase activity, plasma cortisol and the activities of liver detoxification enzymes in rainbow trout Aquatic toxicology 48:265-274 
Bradford MM (1976) A rapid and sensitive method for the quantitation of microgram quantities of protein utilizing the principle of protein-dye binding Analytical biochemistry 72:248-254

Brydges NM, Boulcott P, Ellis T, Braithwaite VA (2009) Quantifying stress responses induced by different handling methods in three species of fish Applied Animal Behaviour Science 116:295-301

Campbell MD, Patino R, Tolan J, Strauss R, Diamond SL (2009) Sublethal effects of catch-and-release fishing: measuring capture stress, fish impairment, and predation risk using a condition index ICES Journal of Marine Science: Journal du Conseil doi:10.1093/icesjms/fsp255

Carlberg I, Mannervik B (1975) Purification and characterization of the flavoenzyme glutathione reductase from rat liver Journal of Biological Chemistry 250:5475-5480

Carr RS, Neff JM (1984) Quantitative semi-automated enzymatic assay for tissue glycogen Comparative Biochemistry and Physiology Part B: Comparative Biochemistry 77:447-449 doi:http://dx.doi.org/10.1016/0305-0491(84)90258-X

Caruso G, Denaro MG, Caruso R, Mancari F, Genovese L, Maricchiolo G (2011) Response to short term starvation of growth, haematological, biochemical and non-specific immune parameters in European sea bass (Dicentrarchus labrax) and blackspot sea bream (Pagellus bogaraveo) Marine environmental 72:46-52 doi:http://dx.doi.org/10.1016/j.marenvres.2011.04.005

Caruso G, Genovese L, Maricchiolo G, Modica A (2005) Haematological, biochemical and immunological parameters as stress indicators in Dicentrarchus labrax and Sparus aurata farmed in off-shore cages Aquaculture International 13:67-73

Cazenave J, Bacchetta C, Rossi A, Ale A, Campana M, Parma MJ (2014) Deleterious effects of wastewater on the health status of fish: A field caging study Ecological Indicators 38:104-112 doi:http://dx.doi.org/10.1016/j.ecolind.2013.10.029

Chilmonczyk S, Monge D (1999) Flow cytometry as a tool for assessment of the fish cellular immune response to pathogens Fish \& shellfish immunology 9:319-333

Craig S, Helfrich LA (2009) Understanding fish nutrition, feeds, and feeding Virginia Cooperative Extension 420-256:1-4

De Andrade VM, da Silva J, da Silva FR, Heuser VD, Dias JF, Yoneama ML, de Freitas TRO (2004) Fish as bioindicators to assess the effects of pollution in two southern Brazilian rivers using the Comet assay and micronucleus test Environmental and Molecular Mutagenesis 44:459-468 doi:10.1002/em.20070

Fenet H, Casellas C, Bontoux J (1998) Laboratory and Field-Caging Studies on Hepatic Enzymatic Activities in European Eel and Rainbow Trout Ecotoxicology and environmental safety 40:137-143 doi:http://dx.doi.org/10.1006/eesa.1998.1654

Frings CS, Fendley TW, Dunn RT, Queen CA (1972) Improved determination of total serum lipids by the sulfo-phospho-vanillin reaction Clin Chem 18:673-674

Frisch A, Anderson T (2000) The response of coral trout (Plectropomus leopardus) to capture, handling and transport and shallow water stress Fish physiology and biochemistry 23:23-34

Gagnaire B et al. (2015) Former uranium mine-induced effects in caged roach: a multiparametric approach for the evaluation of in situ metal toxicity Ecotoxicology 24:215-231 doi:10.1007/s10646-014-1374-8

Gimbo RY, Fávero GC, Franco Montoya LN, Urbinati EC (2015) Energy deficit does not affect immune responses of experimentally infected pacu (Piaractus mesopotamicus) Fish \& shellfish immunology 43:295-300 doi:http://dx.doi.org/10.1016/i.fsi.2015.01.005

Haasch ML, Lech JJ, Prince R, Cooper KR, Wejksnora PJ (1993) Caged and wild fish: Induction of hepatic cytochrome P-450 (CYP1A1) as an environmental biomonitor Environmental toxicology and chemistry 12:885-895 doi:10.1002/etc.5620120513

Habig WH, Pabst MJ, Jakoby WB (1974) Glutathione S-transferases the first enzymatic step in mercapturic acid formation Journal of Biological Chemistry 249:7130-7139 
Hemre GI, Mommsen TP, Krogdahl A (2002) Carbohydrates in fish nutrition: effects on growth, glucose metabolism and hepatic enzymes Aquaculture Nutrition 8:175-194 doi:10.1046/j.1365-2095.2002.00200.x

Henry M, Fountoulaki E (2014) Optimal dietary protein/lipid ratio for improved immune status of a newly cultivated Mediterranean fish species, the shi drum Umbrina cirrosa, L Fish \& shellfish immunology 37:215-219 doi:http://dx.doi.org/10.1016/i.fsi.2014.02.005

Hinck JE et al. (2008) Chemical contaminants, health indicators, and reproductive biomarker responses in fish from rivers in the Southeastern United States The Science of the total environment 390:538-557 doi:10.1016/j.scitotenv.2007.10.026

Hultin HO (1995) Role of membranes in fish quality Fish Quality-Role of Biological Membranes:13-35

Hynes H (1950) The food of fresh-water sticklebacks (Gasterosteus aculeatus and Pygosteus pungitius), with a review of methods used in studies of the food of fishes The journal of animal ecology:36-58

Kiron V (2012) Fish immune system and its nutritional modulation for preventive health care Animal Feed Science and Technology 173:111-133 doi:http://dx.doi.org/10.1016/i.anifeedsci.2011.12.015

Knag AC, Taugb $\varnothing$ A (2013) Acute exposure to offshore produced water has an effect on stress- and secondary stress responses in three-spined stickleback Gasterosteus aculeatus Comparative Biochemistry and Physiology Part C: Toxicology \& Pharmacology 158:173-180 doi:http://dx.doi.org/10.1016/j.cbpc.2013.07.004

Lagadic L, Caquet T, Amiard J (1997a) Biomarqueurs en écotoxicologie: principes et définitions L Lagadic, T Caquet, JC Amiard and F Ramade, Editors, Biomarqueurs en écotoxicologie Aspects fondamentaux, Masson, Paris:1-9

Lagadic L, Caquet T, Amiard J (1997b) Intérêt d'une approche multiparamétrique pour le suivi de la qualité de l'environnement Biomarqueurs en écotoxicologie Aspects Fondamentaux Masson, Paris:393-401

Lall SP (2000) Nutrition and health of fish1

Li X-F, Liu W-B, Lu K-L, Xu W-N, Wang Y (2012) Dietary carbohydrate/lipid ratios affect stress, oxidative status and non-specific immune responses of fingerling blunt snout bream, Megalobrama amblycephala Fish \& shellfish immunology 33:316-323 doi:http://dx.doi.org/10.1016/i.fsi.2012.05.007

Martínez-Álvarez R, Morales A, Sanz A (2005) Antioxidant defenses in fish: Biotic and abiotic factors Rev Fish Biol Fisheries 15:75-88 doi:10.1007/s11160-005-7846-4

Möck A, Peters G (1990) Lysozyme activity in rainbow trout, Oncorhynchus mykiss (Walbaum), stressed by handling, transport and water pollution Journal of Fish Biology 37:873-885

OECD (2000) Eleventh addendum to the OECD guidelines for testing of chemicals. OECD Publishing,

Ohkawa H, Ohishi N, Yagi K (1979) Assay for lipid peroxides in animal tissues by thiobarbituric acid reaction Analytical biochemistry 95:351-358

Oikari A (2006) Caging techniques for field exposures of fish to chemical contaminants Aquatic toxicology 78:370-381 doi:http://dx.doi.org/10.1016/i.aquatox.2006.03.010

Oliva M, Perales JA, Gravato C, Guilhermino L, Galindo-Riano MD (2012) Biomarkers responses in muscle of Senegal sole (Solea senegalensis) from a heavy metals and PAHs polluted estuary Marine pollution bulletin 64:2097-2108 doi:10.1016/j.marpolbul.2012.07.017

Paglia DE, Valentine WN (1967) Studies on the quantitative and qualitative characterization of erythrocyte glutathione peroxidase The Journal of laboratory and clinical medicine 70:158169

Paoletti F, Aldinucci D, Mocali A, Caparrini A (1986) A sensitive spectrophotometric method for the determination of superoxide dismutase activity in tissue extracts Analytical biochemistry 154:536-541

Pascual P, Pedrajas JR, Toribio F, López-Barea J, Peinado J (2003) Effect of food deprivation on oxidative stress biomarkers in fish (Sparus aurata) Chemico-biological interactions 145:191199 doi:http://dx.doi.org/10.1016/S0009-2797(03)00002-4 
Pereira R, Pereira ML, Ribeiro R, Goncalves F (2006) Tissues and hair residues and histopathology in wild rats (Rattus rattus $L$.) and Algerian mice (Mus spretus Lataste) from an abandoned mine area (Southeast Portugal) Environ Pollut 139:561-575 doi:10.1016/j.envpol.2005.04.038

Péry ARR et al. (2014) A Physiologically Based Toxicokinetic Model for the Zebrafish Danio rerio Environmental Science \& Technology 48:781-790 doi:10.1021/es404301q

Pickering AD, Pottinger TG, Christie P (1982) Recovery of the brown trout, Salmo trutta L., from acute handling stress: a time-course study Journal of Fish Biology 20:229-244 doi:10.1111/j.10958649.1982.tb03923.x

Pickering AD, Pottinger TG, Sumpter JP, Carragher JF, Le Bail PY (1991) Effects of acute and chronic stress on the levels of circulating growth hormone in the rainbow trout, Oncorhynchus mykiss General and comparative endocrinology 83:86-93 doi:http://dx.doi.org/10.1016/00166480(91)90108-1

Pompéia C, Lopes LR, Miyasaka CK, Procópio J, Sannomiya P, Curi R (2000) Effect of fatty acids on leukocyte function Brazilian Journal of Medical and Biological Research 33:1255-1268

Pottinger T, Carrick T, Yeomans W (2002) The three-spined stickleback as an environmental sentinel: effects of stressors on whole-body physiological indices Journal of Fish Biology 61:207-229

Regost C, Arzel J, Cardinal M, Laroche M, Kaushik SJ (2001) Fat deposition and flesh quality in seawater reared, triploid brown trout (Salmo trutta) as affected by dietary fat levels and starvation Aquaculture 193:325-345 doi:http://dx.doi.org/10.1016/S0044-8486(00)00498-1

Richter H, Luckstadt C, Schlechtriem C, Focken U, Becker K (2002) Evidence of violation of a basic assumption in models currently used for food consumption estimation in fish Archive of Fishery and Marine Research 49:171-188

Ruane N, Wendelaar Bonga S, Balm P (1999) Differences between rainbow trout and brown trout in the regulation of the pituitary-interrenal axis and physiological performance during confinement General and comparative endocrinology 115:210-219

Sanchez W, Ait-Aissa S, Palluel O, Ditche JM, Porcher JM (2007) Preliminary investigation of multibiomarker responses in three-spined stickleback (Gasterosteus aculeatus L.) sampled in contaminated streams Ecotoxicology 16:279-287 doi:10.1007/s10646-006-0131-z

Sanchez W, Katsiadaki I, Piccini B, Ditche JM, Porcher JM (2008a) Biomarker responses in wild threespined stickleback (Gasterosteus aculeatus L.) as a useful tool for freshwater biomonitoring: a multiparametric approach Environment international 34:490-498 doi:10.1016/j.envint.2007.11.003

Sanchez W, Palluel O, Meunier L, Coquery M, Porcher JM, Ait-Aissa S (2005) Copper-induced oxidative stress in three-spined stickleback: relationship with hepatic metal levels Environmental toxicology and pharmacology 19:177-183 doi:10.1016/j.etap.2004.07.003

Sanchez W, Piccini B, Ditche JM, Porcher JM (2008b) Assessment of seasonal variability of biomarkers in three-spined stickleback (Gasterosteus aculeatus L.) from a low contaminated stream: implication for environmental biomonitoring Environment international 34:791-798 doi:10.1016/j.envint.2008.01.005

Scarcia P, Calamante G, de la Torre F (2014) Biomarker responses in caged carp (Cyprinuscarpio) and native collected fish (Leporinus obtusidens) in the Río de la Plata Estuary, Argentina Environmental toxicology 29:950-960 doi:10.1002/tox.21823

Secombes CJ, Fletcher TC (1992) The role of phagocytes in the protective mechanisms of fish Annual Review of Fish Diseases 2:53-71 doi:http://dx.doi.org/10.1016/0959-8030(92)90056-4

Sumpter JP, Le Bail PY, Pickering AD, Pottinger TG, Carragher JF (1991) The effect of starvation on growth and plasma growth hormone concentrations of rainbow trout, Oncorhynchus mykiss General and comparative endocrinology 83:94-102 doi:http://dx.doi.org/10.1016/00166480(91)90109-J

Tacchi L, Lowrey L, Musharrafieh R, Crossey K, Larragoite ET, Salinas I (2015) Effects of transportation stress and addition of salt to transport water on the skin mucosal homeostasis of rainbow trout (Oncorhynchus mykiss) Aquaculture 435:120-127 doi:http://dx.doi.org/10.1016/i.aquaculture.2014.09.027 
Trenzado CE, Morales AE, Palma JM, de la Higuera M (2009) Blood antioxidant defenses and hematological adjustments in crowded/uncrowded rainbow trout (Oncorhynchus mykiss) fed on diets with different levels of antioxidant vitamins and HUFA Comparative Biochemistry and Physiology Part C: Toxicology \& Pharmacology 149:440-447 doi:http://dx.doi.org/10.1016/j.cbpc.2008.10.105

Trevisan $R$ et al. (2013) Confinement during field studies may jeopardize antioxidant and physiological responses of Nile tilapia to contaminants Marine environmental research 91:97-103 doi:http://dx.doi.org/10.1016/j.marenvres.2013.07.005

Triglidae SB (1998) Field estimates of food consumption of the searobin Prionotus pune tatus (Bloch, 1797) on the continental shelf off Ubatuba, southeastern Brazil Rev bras oceanogr 46:1

Urbinati EC, de Abreu JS, da Silva Camargo AC, Landinez Parra MA (2004) Loading and transport stress of juvenile matrinxã (Brycon cephalus, Characidae) at various densities Aquaculture 229:389-400 doi:http://dx.doi.org/10.1016/S0044-8486(03)00350-8

Valavanidis A, Vlahogianni T, Dassenakis M, Scoullos M (2006) Molecular biomarkers of oxidative stress in aquatic organisms in relation to toxic environmental pollutants Ecotoxicology and environmental safety 64:178-189 doi:10.1016/j.ecoenv.2005.03.013

Vandeputte C, Guizon I, Genestie-Denis I, Vannier B, Lorenzon G (1994) A microtiter plate assay for total glutathione and glutathione disulfide contents in cultured/isolated cells: performance study of a new miniaturized protocol Cell biology and toxicology 10:415-421

Vazzana M, Cammarata M, Cooper E, Parrinello N (2002) Confinement stress in sea bass (Dicentrarchus labrax) depresses peritoneal leukocyte cytotoxicity Aquaculture 210:231-243

Waagb $\varnothing R$ (1994) The impact of nutritional factors on the immune system in Atlantic salmon, Salmo salar L.: a review Aquaculture Research 25:175-197 doi:10.1111/j.1365-2109.1994.tb00573.x 


\section{Figure and table legends}

Table 1: Sticklebac responses (means \pm SEM) according to different caging experiments (biometric data, immune and antioxidant systems, and energy reserves. Measurements of the immune system between the density-starvation and transport experiments were not made with the same flow cytometer. Groups with the same letter ( $\mathrm{a}$ or $\mathrm{b})$ are not significantly different $(\alpha \leq 0.05)$. A star or a point corresponds to a significant difference between the two conditions during transport or starvation experiment, respectively. * Statistical difference for $0.01<\mathrm{p} \leq 0.05$. $* *$ Statistical difference for $0.001<\mathrm{p} \leq 0.01$. *** Statistical difference for $\mathrm{p} \leq 0.001$. K: Fulton's condition index; HSI: hepato-somatic index; Necrosis: leucocyte necrosis; Apoptosis: leucocyte apoptosis; Lympho: Lymphocyte percentage among leucocytes; LMI: lysosomal membrane integrity; ROS b.: ROS basal level; ROS a.: ROS activated level; SI: Stimulation index of respiratory burst; Pg: phagocytic capacity; GSH: total glutathione; GPx: glutathione peroxidase; Gr: glutathione reductase; GST: glutathione-Stransferase; CAT: catalase; SOD: superoxide dismutase; TBARS: thiobarbituric acid reactive substances FU : fluorescence units; W.W.: wet weight.

Figure 1: Characterization (location and physical and chemical parameters) of different caging experiments.

Figure 2: Biometric data according to caging conditions. Results are expressed as ratios of medium and high densities relative to controls kept at a density of $1.08 \mathrm{~kg} / \mathrm{m} 3$, as ratios of sticklebacks without food supply relative to controls with food intake, and as ratios of sticklebacks with transport relative to those without transport. Histograms represent means of ratios \pm SEM. MD: medium density $(2.31 \mathrm{~kg} / \mathrm{m} 3)$; HD: high density (3.54 kg/m3); S: starvation; T: with a short transport (20 minutes); K: Fulton's condition index; HSI: hepatosomatic index. * Statistical difference within an experiment for $0.01<\mathrm{p} \leq 0.05$.

Figure 3: Immune capacities according to caging conditions. Results are expressed as ratios of medium and high densities relative to controls kept at a density of $1.08 \mathrm{~kg} / \mathrm{m} 3$, as ratios of sticklebacks without food supply relative to controls with food intake, and as ratios of sticklebacks with transport relative to those without transport. Histograms represent means of ratios \pm SEM. MD: medium density $(2.31 \mathrm{~kg} / \mathrm{m} 3)$; HD: high density (3.54 kg/m3); S: starvation; T: with a short transport (20 minutes); Necrosis: leucocyte necrosis; Apoptosis: leucocyte apoptosis; Lympho: Lymphocyte percentage among leucocytes; LMI: lysosomal membrane integrity; ROS b.: ROS basal level; ROS a.: ROS activated level; SI: Stimulation index of respiratory burst; Pg: phagocytic capacity. * Statistical difference within an experiment for $0.01<\mathrm{p} \leq 0.05$. ** Statistical difference within an experiment for $0.001<\mathrm{p} \leq 0.01$. *** Statistical difference within an experiment for $\mathrm{p} \leq 0.001$.

Figure 4: Antioxidant system and lipid peroxidation according to caging conditions. Results are expressed as ratios of medium and high densities relative to controls kept at a density of $1.08 \mathrm{~kg} / \mathrm{m} 3$, and as ratios of sticklebacks with transport relative to those without transport. Histograms represent means of ratios \pm SEM. MD: medium density $(2.31 \mathrm{~kg} / \mathrm{m} 3)$; HD: high density $(3.54 \mathrm{~kg} / \mathrm{m} 3)$; S: starvation; $\mathrm{T}$ : with a short transport (20 minutes); GSH: total glutathione; GPx: glutathione peroxidase; Gr: glutathione reductase; GST: glutathione-Stransferase; CAT: catalase; SOD: superoxide dismutase; TBARS: thiobarbituric acid reactive substances; ND: 
not determined. * Statistical difference within an experiment for $0.01<\mathrm{p} \leq 0.05$. ${ }^{*}$ Statistical difference within an experiment for $0.001<\mathrm{p} \leq 0.01$. 


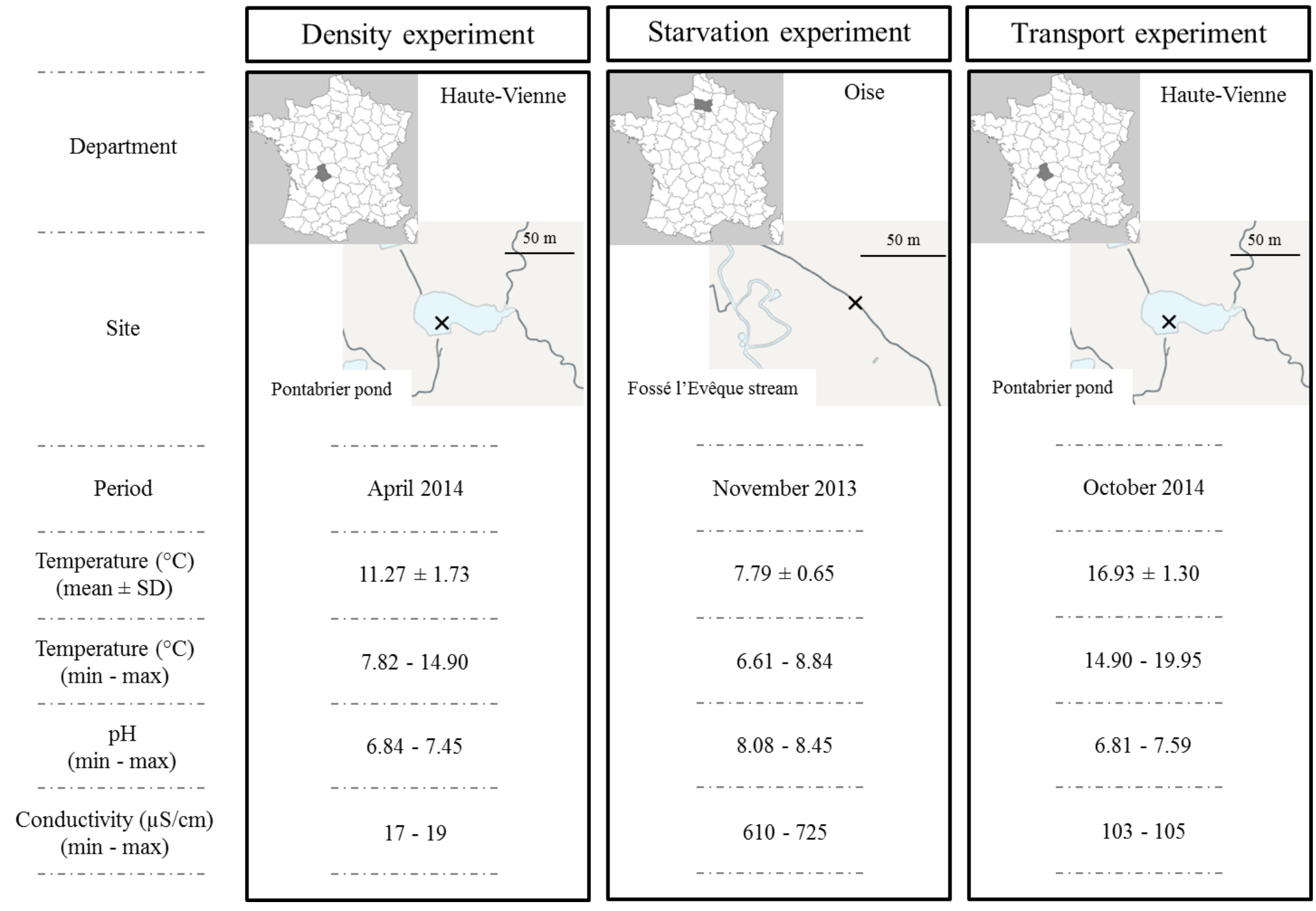

Figure 1: Characterization (location and physical and chemical parameters) of different caging experiments. 
Table 1: Sticklebacks responses (means \pm SEM) according to different caging experiments (biometric data, immune and antioxidant systems, and energy reserves. Measurements of the immune system between the density-starvation and transport experiments were not made with the same flow cytometer. Groups with the same letter (a or b) are not significantly different $(\alpha=5 \%)$. A star or a point corresponds to a significant difference between the two conditions during transport or starvation experiment, respectively. ${ }^{*}$ or $\bullet^{\bullet}$ statistical difference for $0.01<p \leq 0.05$. $* *$ or $\bullet \bullet$ : statistical difference for $0.001<p \leq 0.01$. *** or ${ }^{\bullet \bullet \bullet: ~ s t a t i s t i c a l ~ d i f f e r e n c e ~ f o r ~} p \leq 0.001$. K: Fulton's condition index; HSI: hepato-somatic index; Necrosis: leucocyte necrosis; Apoptosis: leucocyte apoptosis; Lympho: Lymphocyte percentage among leucocytes; LMI: lysosomal membrane integrity; ROS b.: ROS basal level; ROS a.: ROS activated level; SI: Stimulation index of respiratory burst; Pg: phagocytic capacity; GSH: total glutathione; GPx: glutathione peroxidase; Gr: glutathione reductase; GST: glutathione-S-transferase; CAT: catalase; SOD: superoxide dismutase; TBARS: thiobarbituric acid reactive substances $\mathrm{FU}$ : fluorescence units; W.W.: wet weight.

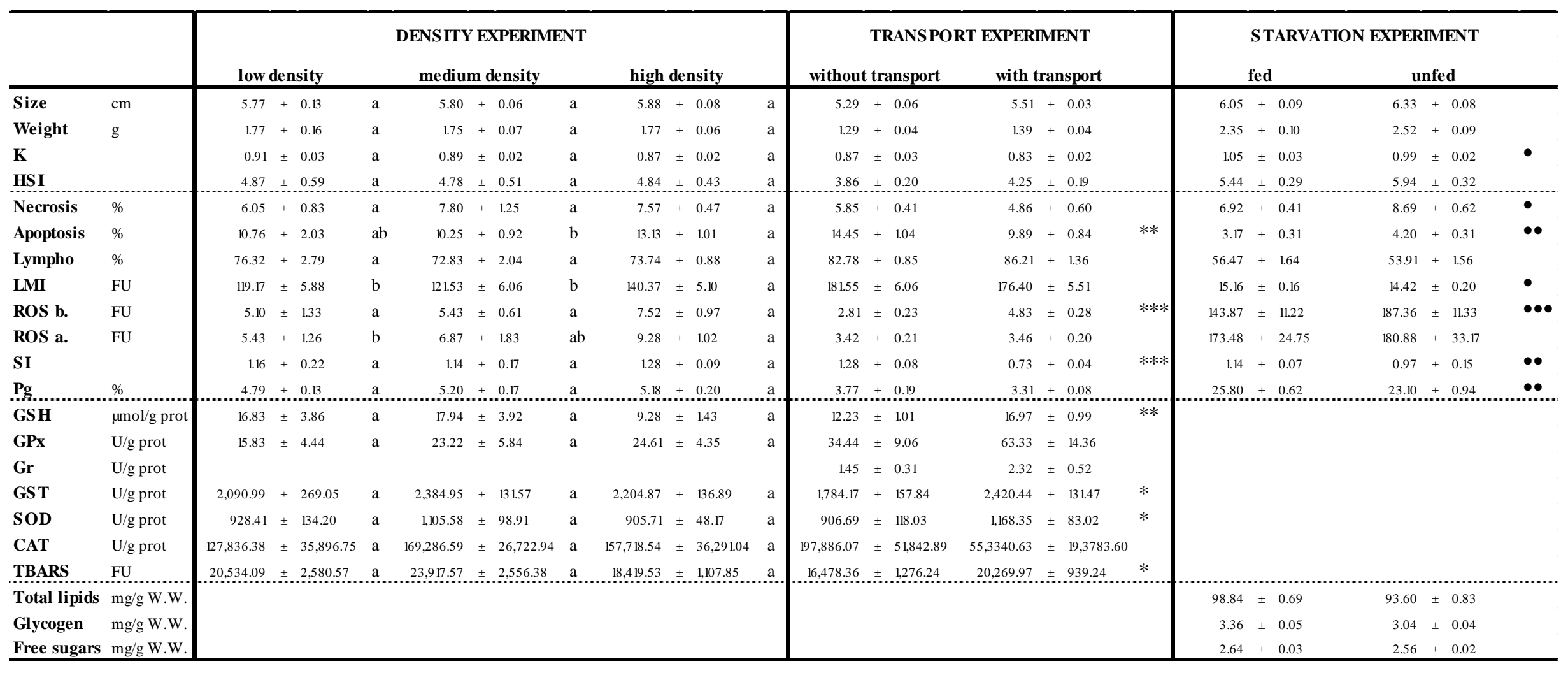




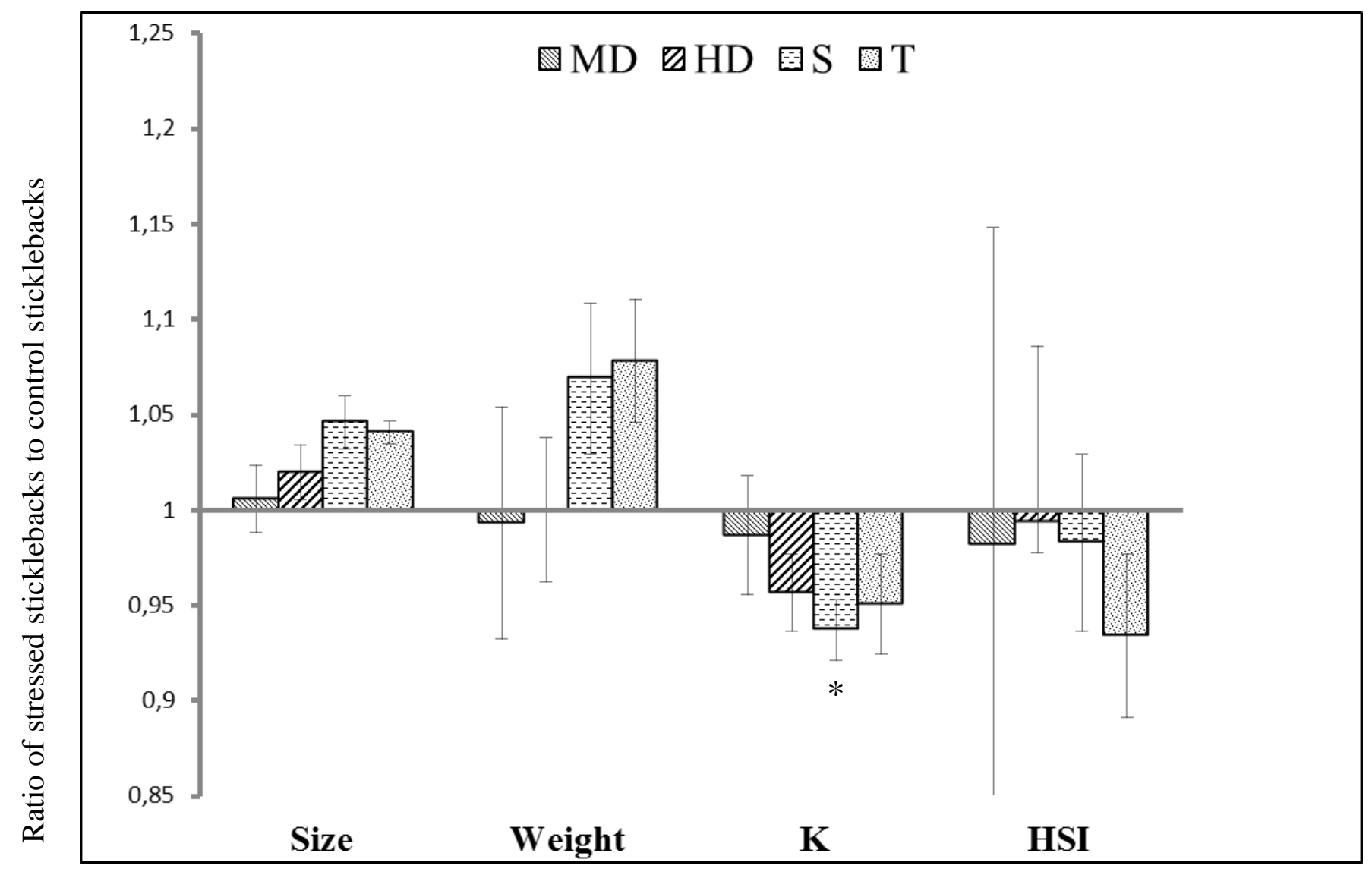

Biometric data

Figure 2: Biometric data according to caging conditions. Results are expressed as ratios of medium and high densities relative to controls kept at a density of $1.08 \mathrm{~kg} / \mathrm{m}^{3}$, as ratios of sticklebacks without food supply relative to controls with food intake, and as ratios of sticklebacks with transport relative to those without transport. Histograms represent means of ratios \pm SEM. MD: medium density $\left(2.31 \mathrm{~kg} / \mathrm{m}^{3}\right)$; HD: high density $\left(3.54 \mathrm{~kg} / \mathrm{m}^{3}\right)$; S: starvation; T: with a short transport (20 minutes); K: Fulton's condition index; HSI: hepato-somatic index. * Statistical difference within an experiment for $0.01<p \leq 0.05$. 


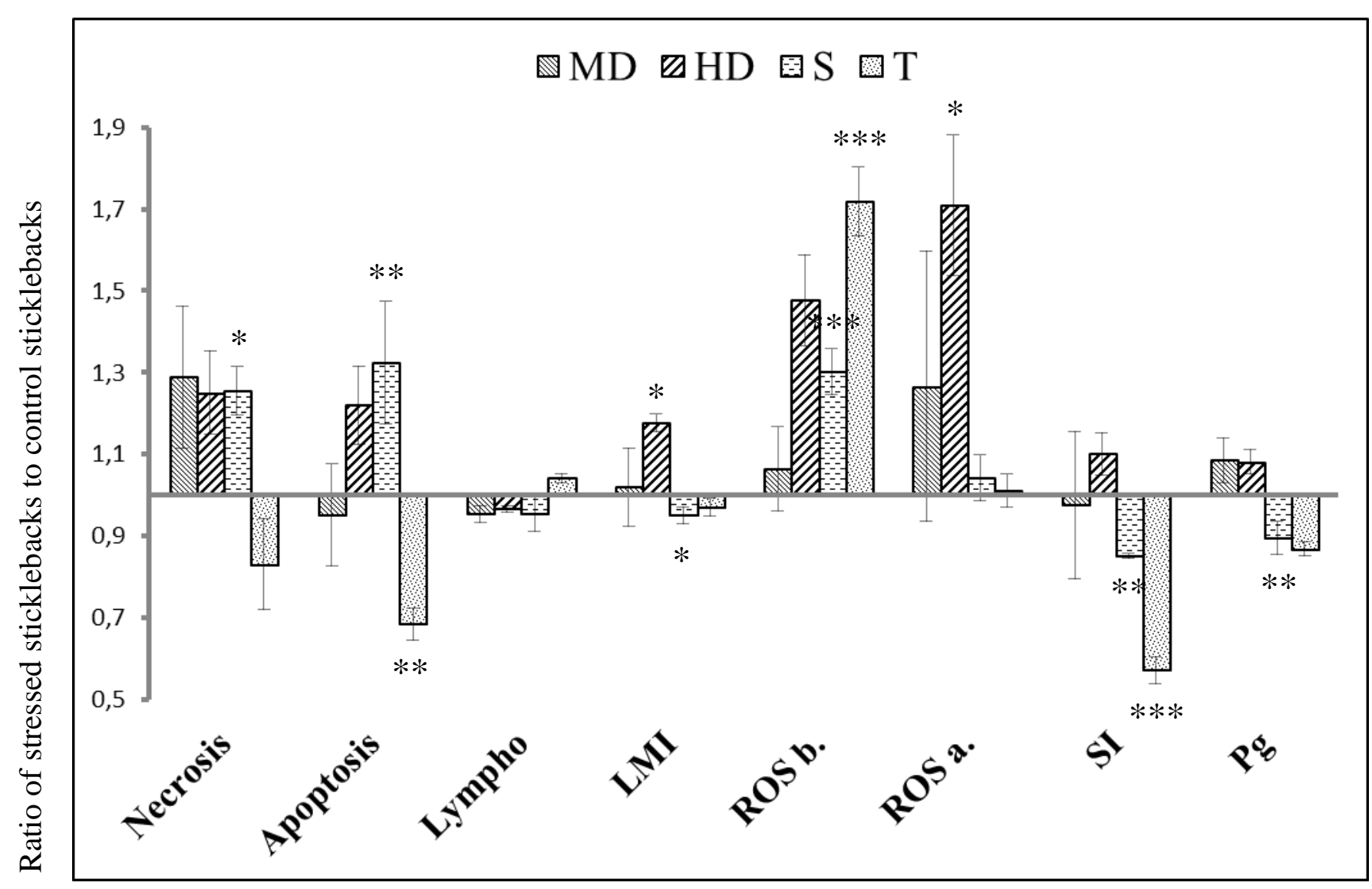

\section{Immune biomarkers}

Figure 3: Immune capacities according to caging conditions. Results are expressed as ratios of medium and high densities relative to controls kept at a density of $1.08 \mathrm{~kg} / \mathrm{m}^{3}$, as ratios of sticklebacks without food supply relative to controls with food intake, and as ratios of sticklebacks with transport relative to those without transport. Histograms represent means of ratios \pm SEM. MD: medium density $\left(2.31 \mathrm{~kg} / \mathrm{m}^{3}\right)$; HD: high density $\left(3.54 \mathrm{~kg} / \mathrm{m}^{3}\right)$; S: starvation; T: with a short transport (20 minutes); Necrosis: leucocyte necrosis; Apoptosis: leucocyte apoptosis; Lympho: Lymphocyte percentage among leucocytes; LMI: lysosomal membrane integrity; ROS b.: ROS basal level; ROS a.: ROS activated level; SI: Stimulation index of respiratory burst; Pg: phagocytic capacity. * Statistical difference within an experiment for $0.01<p \leq 0.05$. ** Statistical difference within an experiment for $0.001<p \leq 0.01$. *** Statistical difference within an experiment for $p \leq 0.001$. 


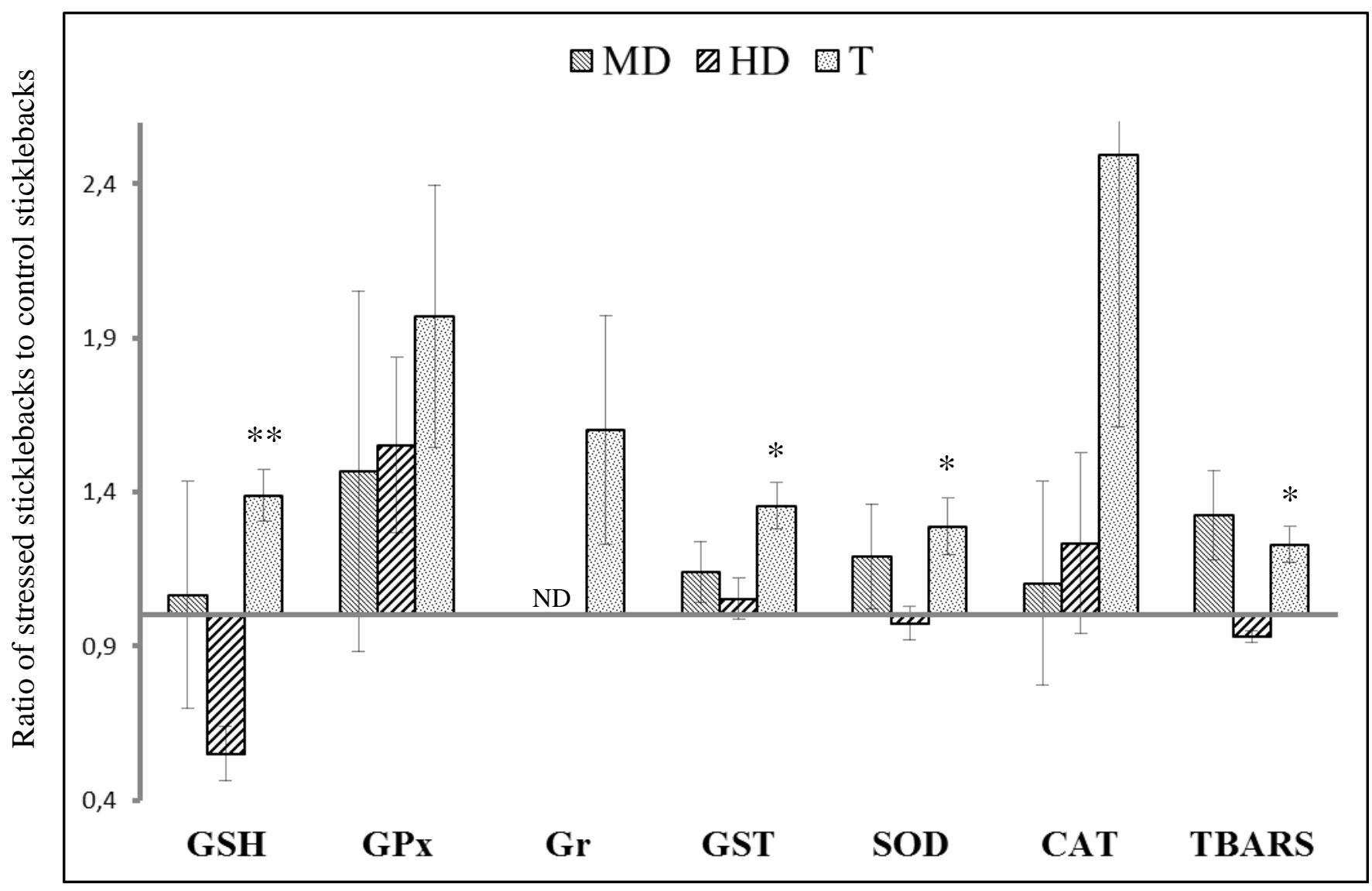

Antioxidant biomarkers and lipid peroxidation

Figure 4: Antioxidant system and lipid peroxidation according to caging conditions. Results are expressed as ratios of medium and high densities relative to controls kept at a density of $1.08 \mathrm{~kg} / \mathrm{m}^{3}$, and as ratios of sticklebacks with transport relative to those without transport. Histograms represent means of ratios \pm SEM. MD: medium density $\left(2.31 \mathrm{~kg} / \mathrm{m}^{3}\right)$; HD: high density $\left(3.54 \mathrm{~kg} / \mathrm{m}^{3}\right)$; $\mathrm{S}$ : starvation; $\mathrm{T}$ : with a short transport $(20$ minutes); GSH: total glutathione; GPx: glutathione peroxidase; Gr: glutathione reductase; GST: glutathione-Stransferase; CAT: catalase; SOD: superoxide dismutase; TBARS: thiobarbituric acid reactive substances; ND: not determined. * Statistical difference within an experiment for $0.01<p \leq 0.05$. ** Statistical difference within an experiment for $0.001<p \leq 0.01$. 